\title{
Regarding some aspects of the reorganization of buildings in the "human-technology-nature" system
}

\author{
Ruben Kazaryan ${ }^{1}$, and Vitaly Khvan ${ }^{1, *}$ \\ ${ }^{1}$ Moscow State University of Civil Engineering, Yaroslavskoe shosse, 26, Moscow, 129337, Russia
}

\begin{abstract}
Reorganization and its variety - building reconstruction accompanies humanity throughout its highly developed existence. Since the formation of the city, three trends have clearly manifested themselves. The first is the sealing of the building in the center of the city, determined by the presence of ambition and prestige, manifested by the most affluent part of the townspeople who prefer to buy more expensive housing. The second is the expansion of the boundaries of cities near which middle-class people live, ensuring the existence of the city as a social conglomerate and serving it in all aspects. The third is the naturally occurring processes of physical and moral deterioration of buildings throughout the city. All these trends define for centuries the urgency of the construction reconstruction that does not reduce its "glow." The article compares the currently known innovative types of building reconstruction, many of which are open. Based on the structural-linguistic information analysis of the aggregate of such types of building reconstruction, the idea of forming a single base of elementary operations and processes of construction production, which allows to form new innovative types of reconstruction as a composition of the elements of this base, is proposed.
\end{abstract}

\section{Introduction}

Reorganization is one of the most common options for human activity. In construction, the reorganization is manifested in the reorganization of buildings and structures, territories and layouts of cities and towns. Reorganization and construction reconstruction organically entered the life of modern man as an obligatory aspect of his life activity and productive labor activity. In the construction of the reconstruction are highlighted (Figure 1): methodological basis; processes and technologies for the organization of activities; components; varieties (traditional and innovative types of construction reorganization).

\footnotetext{
Corresponding author: vitalykhvan95@gmail.com
} 


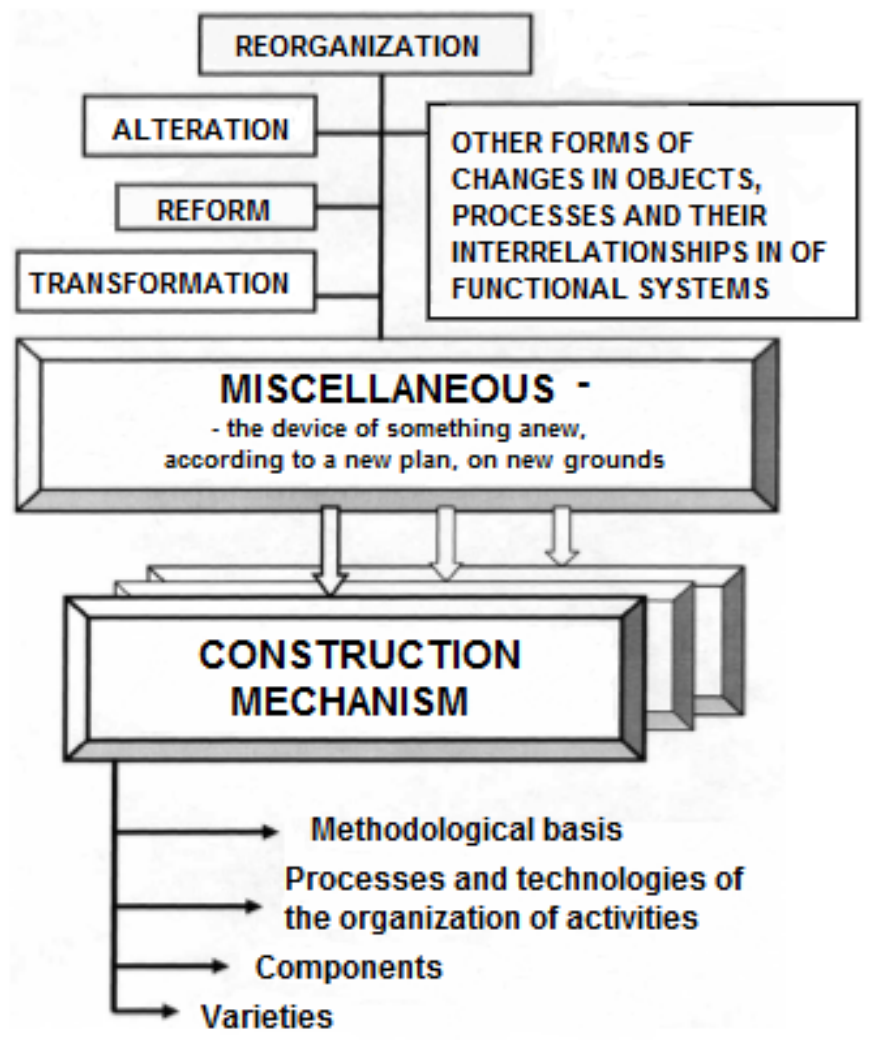

Fig. 1. Construction reconstruction and its characteristics

Among the methodological foundations of building reconstruction are the following: visual-shaped (infographic) modeling; alienation and documentation of models; technology, organization, computerization and intellectualization of activities; management of activities $[1-3,5]$.

\section{Materials and methods}

Comprehensive documentation, infographic, screening, scouting, diagnostics, monitoring, outsourcing, facilitation management, outstaffing, logistics, coaching, engineering, consulting and a number of other known or innovative technologies are used in the construction of the processes and technologies of the organization of activities (partnerships). Since not all of the listed technology activities are familiar to a wide range of readers, we will disclose their meaning [1-10].

Complex documentation is a specific type of human activity, in the process of which information of a certain content is fixed on a document with which many finished processing processes are carried out (quantitative or qualitative change of properties and parameters inherent in the document).

The basic cycle of integrated document processing is a set of possible document processing processes (linguistic qualimetrics, formation and / or adjustment, accumulation, storage, retrieval, reproduction, modification and / or replacement, workflow, destruction).

Infographics is one of the sections of modern technology for processing information resources, the science and practice of graphic expression and visual perception, which 
widely use traditional and computer means of information display and reprographic systems.

Screening - a set of methods and techniques for the preliminary assessment of the situation or trends in the dynamics of changes in the state of the object (object or process).

Scoping - public discussions and hearings on the definition and evaluation of the scope and results of screening.

Diagnostics - the establishment and study of signs that characterize the deviation of the system from the regular mode of operation; development of methods and means of detection and localization of defects. There are express diagnostics, local and complex diagnostics.

Monitoring - a set of repeated observations of the state of the system in space and time with predetermined goals.

Outsourcing is the purposeful allocation of certain business processes in a specific activity and the delegation of their implementation to a third party performer.

Facility manager is a specialist responsible for prompt solution of emerging problems in the mode of saving resources.

Outstaffing (rental of personnel) is the use of labor of temporary employees who are registered with another organization.

Logistics (Greek logistike - to calculate, reason) - optimization of resource flows arising in the process of the functioning of the organization.

Coaching (English coaching - encouraging, training, facilitating) - developing abilities and modeling effective client strategies. The main meaning and distinctive feature of coaching is to help a person find his own solution, and not in solving the problem for him. The coach explains his mission to his client, helps to determine the ways of achieving the goal, to identify the necessary and real resources, to look at himself and his activity in a new way, develop his personal potential, correctly position himself, etc.

Engineering - provision on a commercial basis of various engineering and consulting services executed by the contract (pre-project studies, re-engineering projects, facilities operation technologies, etc.).

Consulting is the sphere of activity, profession and procedure of rendering assistance in the context of personal relations between groups of people who: try to solve a problem or develop a plan (clients); try to help clients (consultants) in this matter.

Components of building reconstruction:

- principles of the organization of labor processes;

- processes of building reconstruction;

- types of work performed;

- building materials and structures;

- Means of mechanization and transportation used;

- principles, technologies and parameters for assessing the quality and comfort of a person in the re-arranged system of "man-technology-habitat, TTS".

\section{Results}

There are two groups of varieties of building reconstruction

- time-tested and not needy, in our opinion, in a detailed explanation;

- emerged in the practice of construction in Russia since 1985, passing the period of its "development", "careful study" and "approval" in the directive and regulatory documentation, and therefore in need of appropriate clarification.

A group of known and time-tested varieties of building reorganization includes repair, reconstruction and restoration. The group of new modern innovative varieties of building 
reconstruction includes recomposition, technical rehabilitation (sanitation), renovation, reversal and retreatment.

Recomposition (recombination, restructuring) - the location of the components of something in a new order with elements of innovation and improved living comfort on a new technical basis (the term Shreiber KA, applied to the construction reconstruction by Ginzburg AV and Kuznetsov SV).

Technical rehabilitation (sanation) - complex restoration of functional systems of a construction site using energy-saving technologies, materials and systems for standard projects without resettlement of tenants, comparable to investment costs with major repair or reconstruction. Measures for complex rehabilitation of buildings are divided into:

- energy-binding (insulation of roofs, attics, facades, basement floors, replacement of windows and balcony doors, renovation of heating systems, hot water supply and ventilation, etc.);

- energy-optional (waterproofing of roofs and foundations, replacement of sanitary equipment, renewal of power supply systems, addition of new or renovation of existing balconies and loggias, repair of staircases, etc.).

Reversal - the change in the purpose, legal status and ownership form of the reorganized object (the term of Chulkov VO, applied to the construction reconstruction of Golubeva $\mathrm{NN}$ ).

Renovation is the compulsory release of the territory (demolition of buildings and structures, extraction of utilities from utilities, networks, etc.) to ensure the possibility of new construction, regardless of the degree of preservation of the buildings located on it (the term Vedeneeva NS and Maklakova TG, applied to the construction of the reconstruction VI Resin in the directive documents of the Government of Moscow). Conditionally the renovation is divided into:

- voluntaristic, compulsory (when a strong-willed decision the object of urban development is demolished);

- evolutionary, naturally occurring (as a result of accumulated errors and unaccounted consequences of not fully controlled and uncontrolled cyclic recombinations and / or reversals).

Evolutionary renovation, as a rule, occurs with reluctance (or lack of possibility) to perform diagnostics and monitoring of the current state of the facility according to its safety criteria. It is the result of the lack of methods and models for recording and analyzing the combination of the results of various local building changes (both officially registered, permitted and recorded, and bypassing the official order) and has its ultimate form of an emergency (accident, destruction of an object or a more serious catastrophe) [1-3,7-9, $11,12]$.

Retrieval (retrieve - retrieve, find) - bringing the reorganized object into working order by attaching a new system to the old functional building system, providing the possibility of replacing the elements of the new system locally or in general (using the assembly / disassembly principle) and ensuring the elimination of the moral deterioration of the building and the normal operation of the facility (the term Kuzina ON, applied to the construction reorganization Chulkov VO and Kuzina ON). The old functional system is considered to be the basic supporting structure of the building, and the new one is the hinged systems for finishing the buildings, structures and their internal premises.

The types of construction reconstruction entering into the second group are the result of a new approach to the analysis of procedures and features of building reconstruction, which reveals common manifestations and the same meaning in various known building technologies.

For example, more than four decades in the domestic construction practice there is a term "renovation" - interior decoration using modern technologies and materials 
(plasterboard, plastic, metal-plastic, glass, etc.). This term gives only a description of the existing practice (what it seems, where it originated, who applies, etc.), but not a constructive concept (does not define the essence of the process, which category it belongs to, what features it has, what it looks like, etc.). More constructive definition of "eurorepair": one of the types of retrieval for internal premises of buildings and structures, using hinged finishing systems. This definition of "eurorepair" allows reasoning and justified to put it in line with such modern technologies for finishing buildings as "office premises", "planar glazing", "ventilated facades", etc. [1-3, 7-15].

The types of building reconstruction that are part of the second group can hardly be called "absolutely new" or "absolutely innovative." An attentive and impartial researcher will discover their manifestation, with more or less activity, at any of the historical stages of domestic and foreign construction practice in the varieties of building reconstruction that are part of the first group. Just to date, they have not been displayed in a holistic, concentrated form as independent varieties of building reconstruction.

In our country, the varieties of building reconstruction of the first group (repair, reconstruction, restoration) are products of the previous social formation, they are focused on maintaining stability (repair of a room or apartment, reconstruction of a building complex or architectural ensemble, restoration of a cultural monument, etc.). The second group of varieties of building reconstruction in modern conditions of management and social structure of our country is aimed at reconstruction (destruction of the existing and creation of a new one) in line with the business approach $[1-3,7-9,16]$.

\section{Discussion}

The positioning of renovation, recomposition, reversal and retrenchment in the current conditions of management and social order can be explained by the beginning of the elimination of a rigid command-administrative directive-normative approach, in the conditions of which these varieties of building reconstruction were "invisible" (there is no this in the norms) [1-3, 7-13].

The list, structure and interrelationships of all the potentially possible characteristics of a construction reorganization in the aggregate never realize simultaneously. Such a set possesses rational redundancy and ensures the mutual compatibility of the varieties of building reconstruction. It is necessary to distinguish and systematize these varieties.

One of the possible formal criteria for distinguishing and systematizing varieties of building reconstruction is the volume (in percent) of the part of the functional resource of the FI originally installed in the project of the re-building construction object. The specific meaning of such a functional resource for each type of building reconstruction is different. For example, in the case of retrieval, such a resource is the area of the interior surface to be decontaminated or the external surface of the reconstructed building or structure. As for the retrieval, the surface that requires decoration is in most cases from $90 \%$ to $100 \%$ of the entire surface of the room (or external surfaces of the external walls of the building or structure), then $\mathrm{FI}>90 \%$.

Based on the results of statistical studies of the activities of modern Russian construction enterprises and organizations, it is possible to indicate the approximate values of FI for each type of construction conversion:

- for a group of known types of building reconstruction (repair, FI $<15 \%$, reconstruction, $\mathrm{FI}<50 \%$, restoration, $\mathrm{FI}>50 \%$ );

- for a group of modern innovative varieties of building reconstruction (recomposition, FI $>30 \%$, rehabilitation technical (sanation), FI $>60 \%$, renovation, FI $<85 \%$, reversal, FI $>85 \%$, retracement, FI $>90 \%$ ). 
The figures given are not normative, but allow us to define the area of reasonably arising to meet the needs of various kinds of new innovative varieties of building reconstruction [1-3, 7-12, 17-19].

\section{Conclusions}

Until the first third of the twentieth century in Russia, the construction of the reconstruction was "repair" in all aspects of its manifestation. From the twenties of the last century and until the time of "perestroika", the officially recognized types of construction reorganization in all normative and directive documents of the construction industry of the Soviet period were "repair," "reconstruction," and "restoration." The meaning of these wellknown terms was fixed in the relevant regulatory documents. Since 1985, and up to the present, the fundamentally altered new forms of relationships in the Russian society have brought to life new innovative types of building reconstruction (renovation, reversion, recomposition, retreatment, etc.), the actual existence of which has been confirmed by the researchers of the building science. In the process of such studies it is possible, from the point of view of the position chosen by the researcher, to note the advantages and disadvantages of each of the innovative types of building reconstruction. this is a new fundamental direction of building reconstruction. Reorganization of buildings in the "human-technology-nature" system - this is a new fundamental direction of building reconstruction. A systematic approach to studying the laws, properties and terminology of this area will provide an understanding of the integrated assessment of the practical understanding of the business processes of building reconstruction in the TTS system "mantechnology-environment" [10-12, 20-25].

\section{References}

1. A.A. Gusakov, Organizational and technological reliability of construction production (in the conditions of automated design systems), 246 (1974)

2. A.E. Semechkin, Organization of reconstruction of urban complexes, 248 (1999)

3. V.O. Chulkov, IOFS Series, 304 (2005)

4. V.O. Chulkov, A.E. Shchegol, G.O. Chulkov, Build. Bull. of the Russ. Engin., 34-35 (2005)

5. V.O. Chulkov, IOFS Series, 1, 352 (2007)

6. O.N. Kuzina, V.O. Chulkov, Infographics in construction: A course of lectures 1, 88 (2014)

7. O.N. Kuzina, V.O. Chulkov, Infographics in construction 2 (2015)

8. A.A. Volkov, V.O. Chulkov, R.R. Kazaryan, R.K. Gazaryan, App. Mech. \& Mat., 584586, 2685-2688 (2014)

9. A.A. Volkov, V.O. Chulkov, R.R. Kazaryan, M.A. Fachratov, O.N. Kyzina, Adv. Mat. Res., 1065-1069, 2585-2588 (2015)

10. A.E. Rozinsky, V. Bulgakov, Organization of experimental housing construction, 161 (1980)

11. O.M. Goryachev, B. Prykina, Features of construction of buildings in crowded conditions (2003)

12. O.M. Goryachev, I.F. Bunkin, B. Prykina, Build. Equip., 49 (2004)

13. Yu.M. Krasny, The manual "Design stroygenplana and organization of the site", 144 (2000)

14. T.N, Tsai, P.G. Hornbeam, V.A. Bolshakov, Prom. \& CET, 426 (1999) 
15. K. Galbraith, A. Galbraith, J.R. Galbraith, Designing Your Organization: Using the STAR Model to Solve 5 Critical Design Challenges (2007)

16. S. Kenneth, R. Jackson, I.J. Jackson, The Contr. Manag. Jrnl., 8 (2001)

17. A.N. Tetior., Hous. Constr., 2, 15-16 (2001)

18. O.N. Kuzina, Russ. Jrnl. of Res. Conser. \& Rec., 1 (2014)

19. I. Shabtai, T. Bockb, Y. Stoliar, Proc Engin, 85, 274-282 (2014)

20. B.A. Lyovin, R.R. Kazaryan, V.O. Chulkov, Infographics of anthropotechnical management. Infographic modeling in the mental activity philosophy., 1 (2016)

21. B.A. Lyovin, R.R. Kazaryan, V.O. Chulkov, Infographics of anthropotechnical management. Conception of advanced development of anthropotechnical security of functioning and life quality., 2 (2016)

22. B.A. Lyovin, R.R. Kazaryan, V.O. Chulkov, Infographics of anthropotechnical management. Anthropotechnical management as a means of provision of activities service., 3 (2016)

23. R.R. Kazaryan, I.A. Bun'kina, Sci. Rev., 7 (2016)

24. A.A. Volkov, V.O. Chulkov, R.R. Kazaryan, M.A. Fachratov, E.K. Rahmonov, App. Mech. \& Mat., 584-586, 2387-2390 (2014)

25. A.A. Volkov, V.O. Chulkov, R.R. Kazaryan, M.A. Fachratov, E.K. Rahmonov, App. Mech. \& Mat., 584-586, 2391-2394 (2014) 